\title{
Salinicoccus sesuvii sp. nov., isolated from the rhizosphere of Sesuvium portulacastrum
}

\author{
Correspondence \\ P. Kämpfer \\ peter.kaempfer@umwelt. \\ uni-giessen.de
}

\author{
P. Kämpfer, ${ }^{1}$ A. B. Arun, ${ }^{2}$ H.-J. Busse, ${ }^{3}$ Chiu-Chung Young, ${ }^{4}$ W.-A. Lai, ${ }^{4}$ \\ P. D. Rekha ${ }^{2}$ and Wen-Ming Chen ${ }^{5}$
}

\author{
${ }^{1}$ Institut für Angewandte Mikrobiologie, Justus-Liebig-Universität Giessen, D-35392 Giessen, \\ Germany \\ ${ }^{2}$ Yenepoya Research Center, Yenepoya University, University Road, Deralakatee, Mangalore, \\ Karnataka, India \\ ${ }^{3}$ Institut für Bakteriologie, Mykologie und Hygiene, Veterinärmedizinische Universität, A-1210 Wien, \\ Austria \\ ${ }^{4}$ College of Agriculture and Natural Resources, Department of Soil and Environmental Sciences, \\ National Chung Hsing University, Taichung, Taiwan, ROC \\ ${ }^{5}$ Laboratory of Microbiology, Department of Seafood Science, National Kaohsiung Marine \\ University, Kaohsiung, Taiwan, ROC
}

\begin{abstract}
A Gram-staining-positive coccus, designated CC-SPL15-2 ${ }^{\top}$, was isolated from the rhizosphere of Sesuvium portulacastrum. By 16S rRNA gene sequence analysis, it was shown that strain CC-SPL15-2 ${ }^{\top}$ belonged to the genus Salinicoccus. The isolate was most closely related to Salinicoccus hispanicus DSM $5352^{\top}$ (98.3\% 16S rRNA gene sequence similarity) and Salinicoccus roseus DSM $5351^{\top}(96.7 \%)$; similarities to all other members of the genus Salinicoccus were $<96.5 \%$. In accordance with characteristics of the genus Salinicoccus, the quinone system was mainly composed of menaquinone MK-6. The polar lipid profile exhibited the major components diphosphatidylglycerol, phosphatidylglycerol and an unidentified glycolipid. In the polyamine pattern, spermidine was the predominant compound. The fatty acids were anteiso- $C_{15: 0}$, iso- $C_{15: 0}$, iso- $C_{16: 0}$ and anteiso- $C_{17: 0}$, which supported the affiliation of strain CC-SPL15-2 $2^{\top}$ to the genus Salinicoccus. DNA-DNA relatedness between strain CC-SPL15-2 ${ }^{\top}$ and S. hispanicus CCUG $43288^{\top}$ was 42 and $32 \%$ (reciprocal analysis). From these data as well as from physiological and biochemical tests, a clear differentiation of strain CC-SPL15-2 ${ }^{\top}$ from $S$. hispanicus and other members of the genus Salinicoccus was possible. We propose that strain CC-SPL15-2 $2^{\top}$ be assigned to a novel species, with the name Salinicoccus sesuvii sp. nov. The

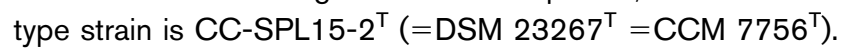

Ventosa et al. (1990) proposed the genus Salinicoccus to contain Gram-staining-positive, catalase- and oxidasepositive, non-motile, non-spore-forming cocci, with MK-6 as the predominant respiratory quinone and a cell wall with

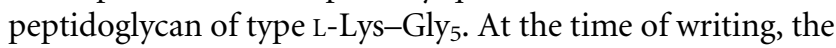
genus comprises 12 species with validly published names: $S$. roseus and S. hispanicus (Ventosa et al., 1990, 1992), S. alkaliphilus (Zhang et al., 2002), S. salsiraiae (França et al., 2006), S. jeotgali (Aslam et al., 2007), S. luteus (Zhang et al., 2007), S. siamensis (Pakdeeto et al., 2007), S. kunmingensis (Chen et al., 2007), S. iranensis (Amoozegar et al., 2008), S. albus (Chen et al., 2009), S. carnicancri (Jung et al., 2010)

The GenBank/EMBL/DDBJ accession number for the 16S rRNA gene sequence of strain CC-SPL15-2 ${ }^{\top}$ is FR669114.

A supplementary figure is available with the online version of this paper. and S. halodurans (Wang et al., 2008). 'S. salitudinis' has also been proposed by Chen et al. (2008).

Strain CC-SPL15-2 ${ }^{\mathrm{T}}$ was isolated from the rhizosphere of Sesuvium portulacastrum (sea purslane) in Budai, Chiayi County, Taiwan, on nutrient agar (Oxoid) at $28{ }^{\circ} \mathrm{C}$. The isolate was maintained on tryptone soy agar at $28{ }^{\circ} \mathrm{C}$. Gram staining and cell morphology were observed by phasecontrast microscopy, as described by Kämpfer \& Kroppenstedt (2004). Gram staining was also examined by the KOH test (Moaledj, 1986).

The 16S rRNA gene was analysed as described previously (Kämpfer et al., 2003). Multiple sequence alignment and analysis were performed using MEGA version 4 (Tamura et al., 2007). Genetic distances were calculated using distance options according to the Kimura two-parameter model, and clustering using neighbour joining and 
maximum parsimony was performed using bootstrap values based on 1000 replications. The 16S rRNA gene sequence of strain CC-SPL15-2 ${ }^{\mathrm{T}}$ was a continuous stretch of $1487 \mathrm{bp}$. Sequence similarity indicated that the closest relatives of strain CC-SPL15-2 ${ }^{\mathrm{T}}$ were S. hispanicus DSM $5352^{\mathrm{T}}$ (98.3\% 16S rRNA gene sequence similarity) and $S$. roseus DSM $5351^{\mathrm{T}}(96.7 \%)$. Similarities to all other members of the genus Salinicoccus were $<96.5 \%$. In the neighbour-joining phylogenetic analysis (Fig. 1), strain CC-SPL15-2 $2^{\mathrm{T}}$ formed a separate lineage in the genus Salinicoccus and clustered with S. hispanicus DSM $5352^{\mathrm{T}}$.

For analysis of the diagnostic cell-wall diamino acid, polyamines, quinones and polar lipids, cells were grown in PYE medium supplemented with sea salts $[0.3 \%$ peptone from casein, $0.3 \%$ yeast extract, $3.1 \%$ sea salts (S9883; Sigma)]. The diagnostic cell-wall diamino acid was extracted and analysed as described by Schleifer (1985). Polyamines were extracted according to Busse \& Auling (1988) from biomass harvested at approximately $70 \%$ maximum $\mathrm{OD}_{600}$, as reported by Altenburger et al. (1997). Polar lipids and quinones were extracted and analysed as described elsewhere (Tindall, 1990a, b; Altenburger et al., 1996). HPLC analysis of quinones and polyamines was carried out using the instrumentation described by Stolz et al. (2007).

The diagnostic cell-wall diamino acid was identified to be lysine, which is in accordance with the description of the genus Salinicoccus (Ventosa et al., 1990). The polyamine pattern of strain CC-SPL15-2 $2^{\mathrm{T}}$ consisted of $\left[(\mathrm{g} \text { dry weight })^{-1}\right]$ $2.2 \mu \mathrm{mol}$ spermidine, $0.1 \mu \mathrm{mol}$ spermine and $0.2 \mu \mathrm{mol}$ putrescine. To the best of our knowledge so far, no polyamine patterns have been reported for any member of the genus Salinicoccus. However, the genus is assigned to the order Bacillales and members of other representative genera of this order, such as Bacillus, Paenibacillus, Alicyclobacillus and Ureibacillus, always exhibit spermidine as a major compound in the polyamine patterns (Hamana et al., 1989; Hosoya et al., 2004). Hence, high amounts of spermidine in the cells are obviously a common trait of representatives of the order Bacillales.

The quinone system of strain CC-SPL15-2 ${ }^{\mathrm{T}}$ was composed of menaquinones, with large amounts of MK-6 (99.8\%) and traces of MK-7 (0.2\%). The polar lipid profile of strain CCSPL15-2 ${ }^{\mathrm{T}}$ was composed of major amounts of diphosphatidylglycerol, phosphatidylglycerol and an unidentified glycolipid and minor amounts of two unidentified lipids not stainable with ninhydrin, molybdenum blue or $\alpha$-naphthol (Supplementary Fig. S1, available in IJSEM Online). The quinone system and polar lipid profile are in excellent agreement with those reported for other members of the genus Salinicoccus, but the two unidentified lipids have not been reported previously. In relation to diphosphatidylglycerol and phosphatidylglycerol, the unidentified glycolipid of strain CC-SPL15-2 ${ }^{\mathrm{T}}$ showed the same chromatographic behaviour as the unidentified glycolipid detected by Ventosa et al. $(1992,1993)$ in the above-mentioned strains of $S$. hispanicus and S. roseus. However, a highly hydrophobic compound is visible in the polar lipid profiles of the type strain of S. hispanicus and a strain of S. roseus (Ventosa et al., 1992, 1993) which probably corresponds to L1 of strain CC-SPL15- $2^{\mathrm{T}}$ because the chromatographic behaviours are similar.

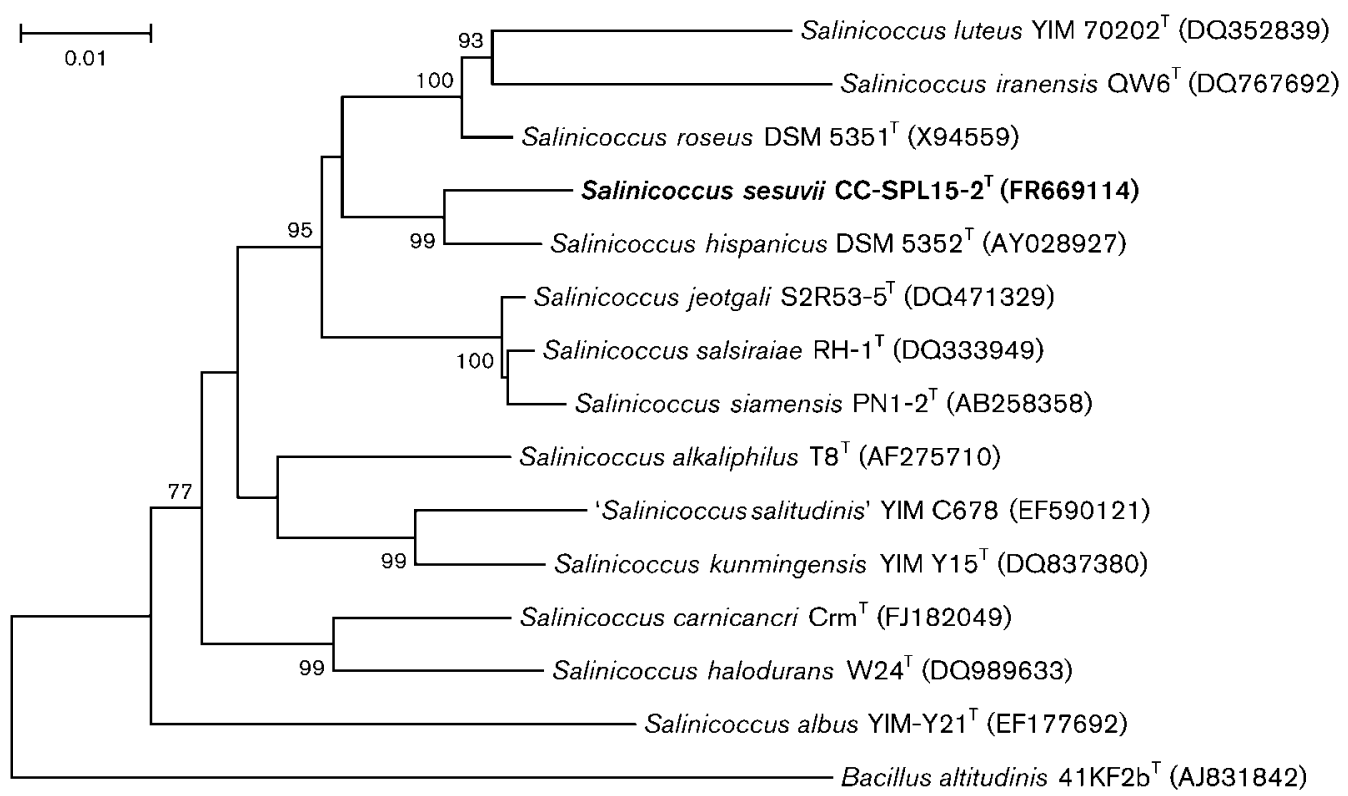

Fig. 1. Neighbour-joining phylogenetic analysis based on 16S rRNA gene sequences, showing the position of strain CCSPL15-2 $2^{\top}$ in the genus Salinicoccus. Bootstrap values ( $\left.>50 \%\right)$ based on 1000 replications are shown at branch nodes. Bar, 0.01 substitutions per nucleotide position. 
Fatty acid analysis was performed according to Kämpfer \& Kroppenstedt (1996). The fatty acid composition of strain CC-SPL15-2 ${ }^{\mathrm{T}}$ was similar to those of members of the genus Salinicoccus and most similar to the fatty acid composition of S. hispanicus CCUG $43288^{\mathrm{T}}$, but some quantitative differences were observed (Table 1). The characteristic fatty acids anteiso- $\mathrm{C}_{15: 0}$, iso- $\mathrm{C}_{16: 0}$ and anteiso- $\mathrm{C}_{17: 0}$ were detected in strain CC-SPL15-2 $2^{\mathrm{T}}$.

The results of the comparative physiological characterization using almost-identical test conditions (Kämpfer et al., 1991) for strain CC-SPL15-2 ${ }^{\mathrm{T}}$ and members of the genus Salinicoccus are given in Table 2 and the species description. DNA-DNA hybridization between strain CC-SPL15-2 ${ }^{\mathrm{T}}$ and S. hispanicus CCUG $43288^{\mathrm{T}}$ was done according to the method of Ziemke et al. (1998) and revealed 42 and $32 \%$ (reciprocal analysis) DNA-DNA relatedness.

Our data demonstrate that strain CC-SPL15-2 ${ }^{\mathrm{T}}$ exhibits traits that are typical of the genus Salinicoccus: for example, the diagnostic diamino acid lysine, a quinone system comprising predominantly menaquinone MK-6 and a polar lipid profile consisting of diphosphatidylglycerol, phosphatidylglycerol and an unidentified glycolipid. The isolate could be distinguished from its closest relative $S$. hispanicus CCUG $43288^{\mathrm{T}}$ and other members of the genus Salinicoccus by physiological traits, DNA-DNA relatedness and differences in 16S rRNA gene sequences. We propose that strain CC-SPL15-2 ${ }^{\mathrm{T}}$ is a representative of a novel species, with the name Salinicoccus sesuvii sp. nov.

Table 1. Fatty acid compositions of strain CC-SPL $15-2^{\top}$ and its closest phylogenetic neighbour in the genus Salinicoccus

Strains: 1, S. sesuvii CC-SPL15-2 ${ }^{\mathrm{T}}$; 2, S. hispanicus CCUG $43288^{\mathrm{T}}$. Data were taken from this study using the TSBA40 database in the MIDI system. ECL, Equivalent chain length. -, Not detected.

\begin{tabular}{|c|c|c|}
\hline Fatty acid (\%) & 1 & 2 \\
\hline iso- $\mathrm{C}_{13: 0}$ & 0.7 & 1.0 \\
\hline iso- $\mathrm{C}_{14: 0}$ & 3.2 & 2.7 \\
\hline $\mathrm{C}_{14: 0}$ & 15.3 & 16.5 \\
\hline iso- $\mathrm{C}_{15: 0}$ & 29.6 & 26.9 \\
\hline anteiso- $\mathrm{C}_{15: 0}$ & 8.6 & 10.1 \\
\hline $\mathrm{C}_{15: 0}$ & - & 0.7 \\
\hline $\mathrm{C}_{16: 1} \omega 7 c$ alcohol & 0.8 & 1.0 \\
\hline iso- $\mathrm{C}_{16: 0}$ & 1.3 & 0.7 \\
\hline Unknown ECL 15.669 & 10.2 & 6.1 \\
\hline $\mathrm{C}_{16: 1} \omega 11 c$ & 5.5 & 12.8 \\
\hline $\mathrm{C}_{16: 0}$ & 13.9 & 11.8 \\
\hline iso- $\mathrm{C}_{17: 1} \omega 10 c$ & 0.9 & 1.4 \\
\hline iso- $\mathrm{C}_{17: 0}$ & 2.0 & 2.4 \\
\hline anteiso- $\mathrm{C}_{17: 0}$ & 0.7 & 0.9 \\
\hline $\mathrm{C}_{18: 0}$ & 2.5 & 2.5 \\
\hline iso- $\mathrm{C}_{19: 0}$ & - & 1.0 \\
\hline $\mathrm{C}_{20: 0}$ & 4.3 & 1.7 \\
\hline
\end{tabular}

\section{Description of Salinicoccus sesuvii sp. nov.}

Salinicoccus sesuvii [se.su'vi.i. N.L. gen. n. sesuvii of Sesuvium, isolated from Sesuvium portulacastrum L. (sea purslane)].

Gram-staining-positive cocci, about $1.0-1.2 \mu \mathrm{m}$ in diameter. Oxidase- and catalase-positive; an oxidative metabolism is shown. Good growth occurs after $48 \mathrm{~h}$ on tryptone soy agar and marine agar 2218 at $28{ }^{\circ} \mathrm{C}$. No growth occurs on MacConkey agar at $28{ }^{\circ} \mathrm{C}$. No growth occurs at 2 or $45{ }^{\circ} \mathrm{C}$. Growth occurs with 1-25\% (w/v) $\mathrm{NaCl}$ [optimum 8 $10 \%(\mathrm{w} / \mathrm{v}) \mathrm{NaCl}]$. Colonies on nutrient agar are smooth, pinkish, circular, translucent and shiny with entire edges. The characteristic diamino acid of the cell wall is lysine. The quinone system is composed mostly of menaquinone MK-6, with traces of MK-7. The polar lipid profile contains major amounts of diphosphatidylglycerol, phosphatidylglycerol and an unidentified glycolipid, and minor amounts of two unidentified lipids. The polyamine pattern contains major amounts of spermidine. The characteristic fatty acids are anteiso- $\mathrm{C}_{15: 0}$, iso- $\mathrm{C}_{15: 0}$, iso- $\mathrm{C}_{16: 0}$ and anteiso- $\mathrm{C}_{17: 0}$. Physiological tests (including differentiating characters obtained using identical conditions) are indicated in Table 2. Acid is weakly produced from D-glucose and maltose, but no acid is produced from sucrose, adonitol, L-arabinose, Darabitol, dulcitol, erythritol, myo-inositol, lactose, melibiose, methyl $\alpha$-D-glucoside, raffinose, L-rhamnose, salicin, Dsorbitol or D-xylose. Urease, indole production and hydrolysis of casein, gelatin, starch, DNA and tyrosine are negative. Aesculin hydrolysis and arginine dihydrolase are positive, but $\mathrm{H}_{2} \mathrm{~S}$ production and lysine decarboxylase, ornithine decarboxylase and $\beta$-galactosidase (ONPG) are negative. Only a few compounds are utilized, among them $\mathrm{N}$-acetyl-D-glucosamine, D-glucose, maltose, pyruvate and DL-lactate. As sole sources of carbon, D-glucose, maltose, D-mannose, D-fructose and trehalose are utilized, but not acetate, propionate, $\mathrm{N}$-acetylgalactosamine, L-arabinose, L-arbutin, cellobiose, D-galactose, gluconate, glycerol, Dmannitol, maltitol, $\alpha$-melibiose, L-rhamnose, D-ribose, sucrose, salicin, D-xylose, adonitol, myo-inositol, D-sorbitol, putrescine, cis-aconitate, trans-aconitate, 4-aminobutyrate, adipate, azelate, fumarate, glutarate, DL-3-hydroxybutyrate, itaconate, 2-oxoglutarate, suberate, citrate, mesaconate, $\mathrm{L}$-alanine, $\beta$-alanine, L-ornithine, L-phenylalanine, L-serine, L-aspartate, L-histidine, L-leucine, L-proline, L-tryptophan, 3-hydroxybenzoate, 4-hydroxybenzoate or phenylacetate. The chromogenic substrate $p$-nitrophenyl- $\beta$-D-glucopyranoside is hydrolysed weakly, but $p$-nitrophenyl- $\alpha$-D-glucopyranoside, $p$-nitrophenyl- $\beta$-D-galactopyranoside, $p$-nitrophenyl- $\beta$-Dxylopyranoside, $p$-nitrophenyl- $\beta$-D-glucuronide, bis- $p$ nitrophenyl-phosphate, bis- $p$-nitrophenylphenylphosphonate, bis- $p$-nitrophenylphosphorylcholine, 2-deoxythymidine$2^{\prime}$ - $p$-nitrophenylphosphate, L-alanine- $p$-nitroanilide, $\gamma$-Lglutamate- $p$-nitroanilide and L-proline- $p$-nitroanilide are not hydrolysed.

The type strain is CC-SPL15-2 ${ }^{\mathrm{T}}\left(=\mathrm{DSM} 23267^{\mathrm{T}}=\mathrm{CCM}\right.$ $\left.7756^{\mathrm{T}}\right)$, isolated from the rhizosphere of Sesuvium portulacastrum. 
Table 2. Differentiating characteristics of strain CC-SPL $15-2^{\top}$ and members of the genus Salinicoccus

Strains: 1, Salinicoccus sesuvii sp. nov. CC-SPL15-2 ${ }^{\mathrm{T}}$; 2, S. albus YIM-Y21 ${ }^{\mathrm{T}}$ (Chen et al., 2009); 3, S. kunmingensis YIM Y15 ${ }^{\mathrm{T}}$ (Chen et al., 2007); 4, S. alkaliphilus $\mathrm{T}^{\mathrm{T}}$ (Zhang et al., 2002); 5, S. roseus DSM 5351 ${ }^{\mathrm{T}}$ (Ventosa et al., 1990); 6, S. hispanicus DSM 5352 ${ }^{\mathrm{T}}$ (Marquez et al., 1990; Ventosa et al., 1992); 7, S. jeotgali S2R53-5 ${ }^{\mathrm{T}}$ (Aslam et al., 2007); 8, S. salsiraiae $\mathrm{RH} 1^{\mathrm{T}}$ (França et al., 2006); 9, S. siamensis PN1-2 ${ }^{\mathrm{T}}$ (Pakdeeto et al., 2007); 10, S. luteus YIM $70202^{\mathrm{T}}$ (Zhang et al., 2007); 11, S. iranensis QW6 ${ }^{\mathrm{T}}$ (Amoozegar et al., 2008). All strains possess MK-6 as the predominant respiratory quinone. O, Orange; OP, orange-pink; P, pinkish; PR, pink-red; RO, reddish orange; $\mathrm{W}$, white; Y, yellow; +, positive; tr, trace; -, negative; ND, no data available.

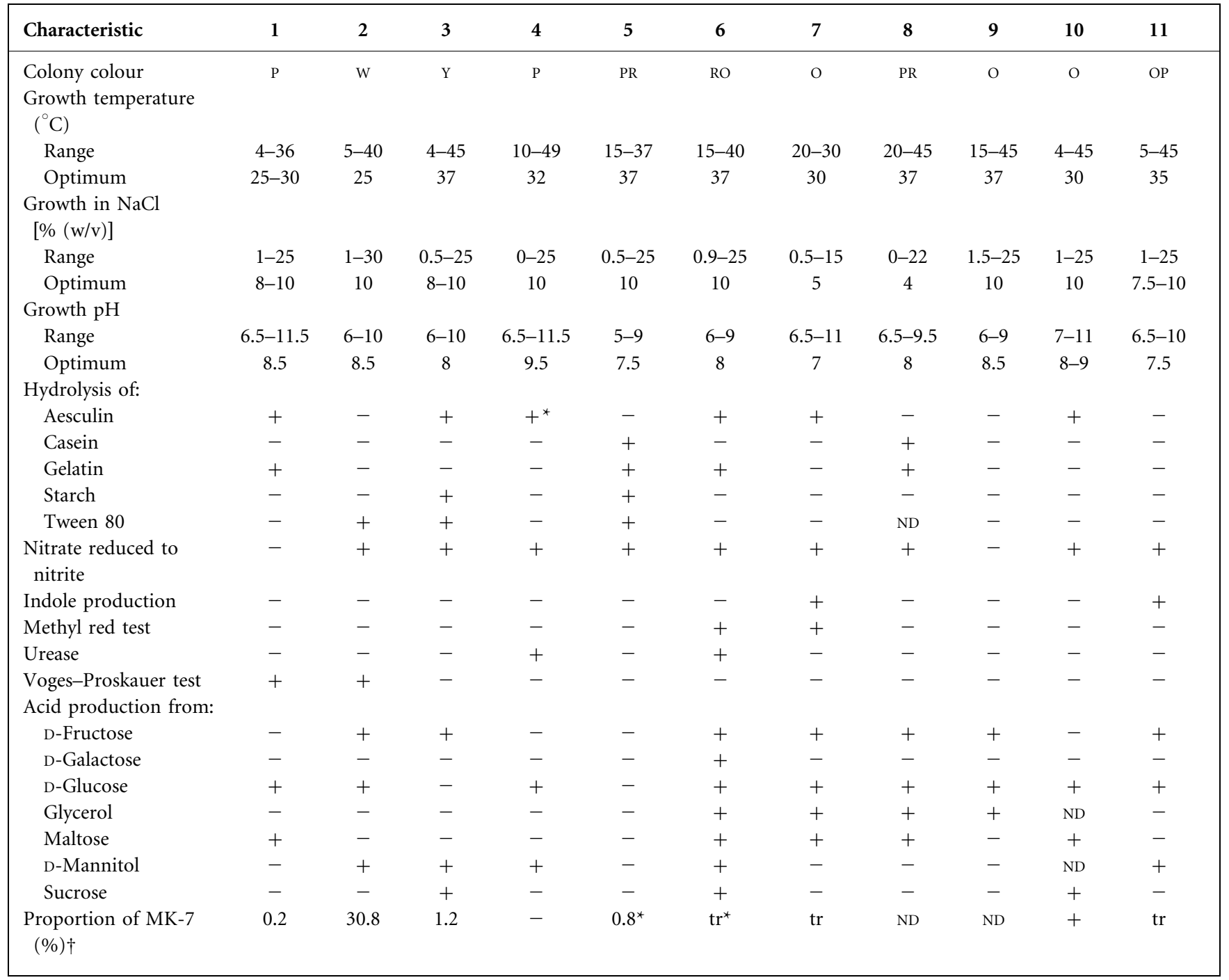

${ }^{\star}$ Data from Chen et al. (2007).

$\dagger$ Percentages of total respiratory quinones are given where available. Data for column 6 by Chen et al. (2007) were confirmed in this study.

\section{Acknowledgements}

We are grateful to Gundula Will and W.-S. Huang for excellent technical assistance and to Jean Euzéby for his advice for the specific epithet.

\section{References}

Altenburger, P., Kämpfer, P., Makristathis, A., Lubitz, W. \& Busse, H.-J. (1996). Classification of bacteria isolated from a medieval wall painting. J Biotechnol 47, 39-52.
Altenburger, P., Kämpfer, P., Akimov, V. N., Lubitz, W. \& Busse, H.-J. (1997). Polyamine distribution in actinomycetes with group B peptidoglycan and species of the genera Brevibacterium, Corynebacterium and Tsukamurella. Int J Syst Bacteriol 47, 270-277.

Amoozegar, M. A., Schumann, P., Hajighasemi, M., Ashengroph, M. \& Razavi, M. R. (2008). Salinicoccus iranensis sp. nov., a novel moderate halophile. Int J Syst Evol Microbiol 58, 178-183.

Aslam, Z., Lim, J. H., Im, W.-T., Yasir, M., Chung, Y. R. \& Lee, S.-T. (2007). Salinicoccus jeotgali sp. nov., isolated from jeotgal, a traditional Korean fermented seafood. Int J Syst Evol Microbiol 57, 633-638. 
Busse, H.-J. \& Auling, G. (1988). Polyamine pattern as a chemotaxonomic marker within the Proteobacteria. Syst Appl Microbiol 11, 1-8.

Chen, Y.-G., Cui, X.-L., Pukall, R., Li, H.-M., Yang, Y.-L., Xu, L.-H., Wen, M.-L., Peng, Q. \& Jiang, C.-L. (2007). Salinicoccus kunmingensis sp. nov., a moderately halophilic bacterium isolated from a salt mine in Yunnan, south-west China. Int J Syst Evol Microbiol 57, 2327-2332.

Chen, Y. G., Cui, X. L., Li, W. J., Xu, L. H., Wen, M. L., Peng, Q. \& Jiang, C. L. (2008). Salinicoccus salitudinis sp. nov., a new moderately halophilic bacterium isolated from a saline soil sample. Extremophiles 12, 197-203.

Chen, Y.-G., Cui, X.-L., Wang, Y.-X., Zhang, Y.-Q., Li, Q.-Y., Liu, Z.-X., Wen, M.-L., Peng, Q. \& Li, W.-J. (2009). Salinicoccus albus sp. nov., a halophilic bacterium from a salt mine. Int J Syst Evol Microbiol 59, 874-879.

França, L., Rainey, F. A., Nobre, M. F. \& da Costa, M. S. (2006). Salinicoccus salsiraiae sp. nov.: a new moderately halophilic grampositive bacterium isolated from salted skate. Extremophiles 10, 531536.

Hamana, K., Akiba, T., Uchino, F. \& Matsuzaki, S. (1989). Distribution of spermine in bacilli and lactic acid bacteria. Can J Microbiol 35, 450-455.

Hosoya, R., Hamana, K., Niitsu, M. \& Itoh, T. (2004). Polyamine analysis for chemotaxonomy of thermophilic eubacteria: polyamine distribution profiles within the orders Aquificales, Thermotogales, Thermodesulfobacteriales, Thermales, Thermoanaerobacteriales, Clostridiales and Bacillales. J Gen Appl Microbiol 50, 271-287.

Jung, M.-J., Kim, M.-S., Roh, S. W., Shin, K.-S. \& Bae, J.-W. (2010). Salinicoccus carnicancri sp. nov., a halophilic bacterium isolated from a Korean fermented seafood. Int J Syst Evol Microbiol 60, 653-658.

Kämpfer, P. \& Kroppenstedt, R. M. (1996). Numerical analysis of fatty acid patterns of coryneform bacteria and related taxa. Can $J$ Microbiol 42, 989-1005.

Kämpfer, P. \& Kroppenstedt, R. M. (2004). Pseudonocardia benzenivorans sp. nov. Int J Syst Evol Microbiol 54, 749-751.

Kämpfer, P., Steiof, M. \& Dott, W. (1991). Microbiological characterisation of a fuel-oil contaminated site including numerical identification of heterotrophic water and soil bacteria. Microb Ecol 21, 227-251.

Kämpfer, P., Dreyer, U., Neef, A., Dott, W. \& Busse, H.-J. (2003). Chryseobacterium defluvii sp. nov., isolated from wastewater. Int J Syst Evol Microbiol 53, 93-97.

Marquez, M. C., Ventosa, A. F. \& Ruiz-Berraquero, F. (1990). Marinococcus hispanicus, a new species of moderately halophilic gram-positive cocci. Int J Syst Bacteriol 40, 165-169.
Moaledj, K. (1986). Comparison of Gram-staining and alternate methods, $\mathrm{KOH}$ test and aminopeptidase activity in aquatic bacteria: their application to numerical taxonomy. J Microbiol Methods 5, 303310.

Pakdeeto, A., Tanasupawat, S., Thawai, C., Moonmangmee, S., Kudo, T. \& Itoh, T. (2007). Salinicoccus siamensis sp. nov., isolated from fermented shrimp paste in Thailand. Int J Syst Evol Microbiol 57, 2004-2008.

Schleifer, K. P. (1985). Analysis of the chemical composition and primary structure of murein. Methods Microbiol 18, 123-156.

Stolz, A., Busse, H.-J. \& Kämpfer, P. (2007). Pseudomonas knackmussii sp. nov. Int J Syst Evol Microbiol 57, 572-576.

Tamura, K., Dudley, J., Nei, M. \& Kumar, S. (2007). MEGA4: Molecular Evolutionary Genetics Analysis (MEGA) software version 4.0. Mol Biol Evol 24, 1596-1599.

Tindall, B. J. (1990a). A comparative study of the lipid composition of Halobacterium saccharovorum from various sources. Syst Appl Microbiol 13, 128-130.

Tindall, B. J. (1990b). Lipid composition of Halobacterium lacusprofundi. FEMS Microbiol Lett 66, 199-202.

Ventosa, A., Marquez, M. C., Ruiz-Berraquero, F. \& Kocur, M. (1990). Salinicoccus roseus gen. nov., sp. nov., a new moderately halophilic gram-positive coccus. Syst Appl Microbiol 13, 29-33.

Ventosa, A., Marquez, M. C., Weiss, N. \& Tindall, B. J. (1992). Transfer of Marinococcus hispanicus to the genus Salinicoccus as Salinicoccus hispanicus comb. nov. Syst Appl Microbiol 15, 530-534.

Ventosa, A., Marquez, M. C., Kocur, M. \& Tindall, B. J. (1993). Comparative study of "Micrococcus sp." strains CCM 168 and CCM 1405 and members of the genus Salinicoccus. Int J Syst Bacteriol 43, 245-248.

Wang, X., Xue, Y., Yuan, S., Zhou, C. \& Ma, Y. (2008). Salinicoccus halodurans sp. nov., a moderate halophile from saline soil in China. Int J Syst Evol Microbiol 58, 1537-1541.

Zhang, W., Xue, Y., Ma, Y., Zhou, P., Ventosa, A. \& Grant, W. D. (2002). Salinicoccus alkaliphilus sp. nov., a novel alkaliphile and moderate halophile from Baer Soda Lake in Inner Mongolia Autonomous Region, China. Int J Syst Evol Microbiol 52, 789-793.

Zhang, Y.-Q., Yu, L.-Y., Liu, H.-Y., Zhang, Y.-Q., Xu, L.-H. \& Li, W.-J. (2007). Salinicoccus luteus sp. nov., isolated from a desert soil. Int $J$ Syst Evol Microbiol 57, 1901-1905.

Ziemke, F., Höfle, M. G., Lalucat, J. \& Rosselló-Mora, R. (1998). Reclassification of Shewanella putrefaciens Owen's genomic group II as Shewanella baltica sp. nov. Int J Syst Bacteriol 48, 179-186. 